\section{(B) lizeriationz}

\author{
on
}

\section{MALIGNANT GRANULOMA OF THE NOSE. \\ BY}

Sir ROBERT WOODS, M.Ch.(HoN.), F.R.C.S.I., HONORARY PROFYSSOR OF LARYNGOLOGY, TRINITY COLLEGE, DUBLIN; LARYNGOLOGIST TO SIR PATRICK DUN'S HOSPITAL.

\section{[With Special Plate.]}

I venture to think that the following two cases of a disease hitherto, as far as I know, undescribed are of sufficient interest to deserve a detailed description.

\section{CASE I.}

X., a man aged 68, consulted me in February, 1914, complaining of his nose. He was a big and robust countryman who had never had any serious illness in his life. His account of himself was very definite. He had never had occasion to consult a doctor for anything of inportance, except when, on June 29th, 1869, he saw the late Sir William Wilde on account of "darkness" of the right eye. He left Sir William because he considered he proved lis incompetence by suspecting him of having had venereal disease; and he nerer saw any doctor or had any treatment for any ailment until he was sent to me by Dr. Kerrigan in February; 1914 . The eye was then no worse than it was in 1869, and for anything the patient knew it was no worse in 1869 than when he w'as born, but he discovered that it was "dark" at that time

In 1905 he lost both taste and smell, but had no other trouble until Deccmber, 1913, when he found the nose blocked.

On examination, the bridge of the nose was sunken just below the nasal bones. The region of the right lacrymal sac was swollen, and a fistula below the internal canthus discharged a watery fluid on to the cheek. Both sides of the nose were filled with fetid crusts, the cartilaginous septum was gone, some of the soft tissues were deficient, and the walls of the nose in a condition of ulceration. The patient was well nourished, appetite good, no glands were enlarged, and the disease was strictly a local one. Syphilis was naturally at first thought of, but it soon became quite evident that it had nothing to do with the complaint. The foetor was quite peculiar, and quite unlike anything I cver before experienced; the crusts were glutinous, and adhered tightly to the forceps used for their removal. A specimen of blood was taken and found to be quite normal; the Wassermann test was negative; salvarsan was administered intravenously, mercury and potassium iodide wore prescribed, but all without the slightest obvious effect on the disease. Specimens of the ulcerated surfaces were repeatedly removed, sometimes fòr diagnostic purposes, sometimes in the course of scraping operations preparatory to the applications of caustics. In every case examination showed granulation tissue to be the domiuant feature, but in one place at least it had developed into something very like a sarcoma. Tiodine was injected subcutaneously for a considerab!e time; but it, too, was without obvious: effect. The blood was several times tested for Wassermann's reaction after treatment with antisyphilitic drugs, but always with a negative result. The patient was lrept in Sir Patrick Dun's Hospital for some weeks, during which time his temperature remained normal, and was then sent home. On his return about two months later the left lacrymal sac was swollen as the right originally was, and the fistula on the right side had healed.

The patient attended $m e$ at the hospital intermittently during 1915 without any substantial gain in his local condition or impairment of his general health. In the early months of 1916 the disease, which had hitherto been marked by the absence of obvious tumour, began to infiltrate the soft palate and back of the nose. In June of that year a necrotic area began to develop in the right side of the soft palate, and towards the end of July had perforated the palate, leaving a large hole about the size of a sixpenny bit.
Deafness from Eustachian obstruction was very marked and as all attempts at cathelerization failed, relief had to be given by myringotomy, which had to be repeated whenever the wound in the membrane healed. Some awkwardness in swallowing resulted from the perforation in the palate.

My colleague, Dr. Watson, who saw him with me in consultation, kindly undertook to try the therapeutic effects of $x$ rays. 'This treatment was carried out at the end of July and during the month of August. No improvement resulted, and when I saw him on September 17th the soft palate was infiltrated in its whole extent, the perforation had increased in size, the increase being towards the middle line, so that the defect was about equally distributed on either side of the middle line. The edges of the perforation were very definite and sharp; quite rectangular on section. 'The floor of the ulcer was covered with a greyish slough; there was some redness at the edges.

By November, 1916, the ulceration had progressed in the palate, though it secmed stationary elsewhere, but this extension was irregular, the ulcer branched in the direction of the last right upper molar where the alveolar riclge was expesed and necrotic. He was again put on large doses of potassium iodide up to 20 grains three times a day. Myringotomy was performed every few weeks for the relief of deafness.

The patient's condition became steadily worse. The septum and turbinal tissues, including the turbinal bones, were completely destroyed, but the tissues of the face were never attacked. He ceased to attend hospital, and died at home in October, 1918, four years and a half after the onset of the disease. 'The progress of the disease could not be described as painful. The discomfort, though sometimes considerable, was never so great as to call for auodynes.

The case was as puzzling to the pathologists as to the clinicians. It seemed as if a wave of granulation tissue advanced irregularly into the healthy parts, breaking down behind as it advanced in front, so that there was never any great depth of pathological growth present. The term " malignant granuloma" vas suggested by Dr. O'Sullivan, and I can think of no better label. Efforts were repeatedly made to discover some organism to which blame might be attached, but always without success.

\section{CASE II.}

The second case was that of a labourer in a. wholesale store, aged 67, who was first seen by me in February, 1920. He had been complaining of discomfort in the nose for some weeks. He was a pale but organically healthy man who had not previously had any notable illness.

On examination, both sides of the nose were filled with the same glutinous crusts, with the same characteristic smell as in the other case. The quadrilateral cartilage was almost completely destroyed, and the crusts were firmly adherent to the edges of the perforation. .The ulcer appeared to be spreading along the floor of the left nose. There was no sinking in of the nose below the bridge. Careful inquiry could elicit nothing in his previous history suspicious of syphilis, but as an aid to exclusion a specimen of his blood was examined by the Wassermann test, with a negative result. A specimen of the ulcerated tissue was removed for microscopic examination. It showed a very cellular granulation tissue invading the nasal cartilage; many polymorphs in the tissue. There were a few fibres, and the vessel walls were not thickened. Mercury and potassium iodide were prescribed, and a dose of novarsenobillon was administered intravenously on February 12th, 1920. A week after this injection a necrotic area appeared in the roof of the mouth on the left side of the hard palate. Through the floor of the slough necrosed bone could be felt by the probe. This necrotic patch measured about $10 \mathrm{~mm}$. fore and aft and $6 \mathrm{~mm}$. across. Blood was again sent for Wassermann test, with a negative report.

The condition of the patient grew steadily worse. The necrosis spread to the neighbouring parts of the maxilla, burrowing under the tissues of the cheek. Pain of a most severe neuralgic character set in, thre nose and left side of the face were so exquisitely tender that he could not bear being dressed, and sleep became impossible without drugs. He even acquired a peculiar gait, moving cautiously from 
one foot to the other, lest the jar of putting his heel heavily on the ground should hurt him.

By the beginning of June the nasal process and a large adjacent portion of the left maxilla was isolated and necrotic. The tissues of the face were attacked above the fold of the nostril and necrosed, leaving a large perforation with tender granular edges between the nose and the cheek, through which the dead bone could be seen and felt over a large area.

The treatment adopted during this time consisted in cauterization of the ulcerated surfaces by chemical caustics, such as acid nitrate of mercury; but though these appeared to arrest the disease now and then in places, it was quite evident that the general trend of the malady was from bad to worse.

We decided to try the effect of radium emanations, and accordingly, in June, four tubes obtained from the Laboratory of the Royal Dublin Society, of about 12 millicuries activity, in steel needles wrapped with tea lead, were placed through the perforation in the palate and left in for eighteen hours. In about two weeks it was quite evident that great improvement had resulted. The posterior part of the palatal perforation had epithelialized, and was no longer tender to the probe. A second $\bullet$ dose of radium was given on July 17th, consisting of six tubes of about 20 millicuries activity in steel needles covered with eight wrappings of pure tinfoil. The needles were embedded in dental wax and left in for eighteen hours. In ten days the change was striking. The swelling had subsided, the tenderness reduced to a trifle, and the pain had eased off to such an extent that the patient had no difficulty in sleeping without drugs. Improvement was sustained, and in October the front of the left maxilla, which had become quite loose, was easily removed through the palatal perforation.

He put on flesh rapidly in the latter half of 1920, and remained quite well until Easter of this year, when a swelling appeared on the inner wall of the left nose near the body of the sphenoid. It was certainly a recurrence but subsided within ten days after an exposure of 360 millicurie bours of emanation, screened through two layers of tea lead.

At my invitation the patient was seen in June by my Jaryngological colleagues Drs. Dempsey, Gogarty, Graham Keogh, and Law, all of whom confessed that the case was unique in their experience.

One must hesitate before concluding that a case belongs to a new class, even though its clinical features differ from everyday experience. The vagaries of syphilis in particular are so notorious that the greatest caution must be exercised. I felt that in these cases syphilis was the one disease that needed the most rigorous exclusion. Not being a believer in the constancy of the Wassermann reaction in syphilis I placed no reliance on a negative report, though I am of opinion that, at least in the second case, the acuteness of the disease was such that the negative Wassermann amounted to a positive exclusion But when, in addition to this and other evidence, all the best tried and most valued remedies are applied as they were in both these cases, without the least effect on their progress, the case for its exclusion is overwhelming.

There remains to be considered the nature of the process in these two cases, for, although differing from one another in some important respects, their similarities make it likely that they resulted from the same cause.

- Granulation tissue is usually the result of that attempt at repair that follows tissue destruction, and when the cause of destruction is bacterial there is little difficulty nowadays in recognizing the organism. In these cases no such organism could be found, and the presumption is raised that the granulation tissue, so far from being an evidence of attempted healing, is itself the primary cause of destruction.

- Until we understand what is meant by a cell taking on malignant action we cannot doubt that what happens to one kind of cell may happen to another, and if wo can have a malignant epithelioma, why not malignant granuloma?

The pathological side of the question, while of the highest interest and importance, must from the clinician's point of view give place to the interest attaching to the fact that the first case failed to be cured by $x$ ray, and the second was certainly cured by radiun.

\section{INFECTIVE EXTERNAL HYDROCEPHALCS ("SHIFTING EPILEPSY").}

BY

CECIL E. REYNOLDS, M.D., D.P.H., II.R.C.S., LOS ANGELES.

[With Special Plate.]

The following case, at one time or another, presented all the symptoms of the various other cases of epilepsy due to localized hydrocephalus which I have reported elsewhere.

\section{History}

L. H. female, born October 29th, 1911, of good stock, was healthy until she had whooping-cough in June, 1916, the cough of which dragged on until December, 1916, during which month she had sore throat and fever. Her tonsils were remored in January, 1917. From this time until March she would cry out in her sleep. During March she contracted a habit of constantly rubbing the palm of the right hand upon the head of her "Teddy Bear," and when questioned, said her hand itched. Later in March, 1917, she ran to her mother during the day with her right hand in a state of involuntary flexion. This contraction was repeated with increasing frequency and severity, and in a few weeks it became so strong as to resist her father's efforts to open the hand. Consciousness was unaffected in these attacks. In April, 1917, it was discovered that she was having, about four times a night, attacks in which the whole body stiffened and the right arm was convulsed. The attacks from June onward became solely nocturnal, and were more severe and fre. quent, especially after a febrile attack in July, in which the temperature was $103^{\circ}$. Her memory appeared to be failing. During this time she complained often of headache "all over," and of nausea, but seldom if ever vomited; she was obstinately constipated, and her nose bled almost every week. The appetite was poor, but the diet had been greatly restricted. A Wassermann test of the blood was negative. The condition became steadily worse, until about October 5th she was having almost continuous fits every night, and on October 18th remained unconscious, cyanosed and rigid for so long that death was expected.

On October 19th, 1918, I met Di. J. H. Utley and Dr. William A. Edwards in consultation, and, operation being agreed upon, she was admitted to the California Hospita] under my care.

Condition on Admission.

The patient is a fairly well nourished child of 7 jears mentally bright to the point of precocity, over-restless, and inclined to laugh hysterically, good tempered, walks " pigeon toed," the right foot being more inverted. "The optic discs have clear, sharp margins; the temporal sides are rather pale, and the veins a trifle large. Alternating internal strabismu definitely present though slight. Slight lateral nystagmus to the left seen once. Pupils normal in size and contour, equal, and react well to light and accommodation. Slight weakness of the right angle of the mouth when at rest and on voluntary movement. No other muscular weakness discernible but although right-handed, she is at least as strong in her left hand as her right. Sensation everywhere very keen and well as her right. Sensation everywhere very keen and well localized. Slight Rombergism present. Position sense of righ arm rather less certain. Arm co-ordination excellent an pointing normal. Knee-jerks equal and exaggerated. No ankle clorus, plan

Before she was soundly asleep at night the fits began with tonic contraction of the flexors of the body, extension and adduction of the arms, and extenson of the knees with flexion of the hips. The emprosthotonos was so great that the head nearly touched the thighs. Shortly afterwards there occurrec blinking movements of the eyelids, the right angle of the mouth was drawn clonically to the right, the formerly extended righ wrist was clonically flexed and the convulsion spread to the right arm. The left arm and both legs remained rigid throughout. During some fits she would awaken whilst the right arm and face were in clonus, and ask to have them stopped. Often she awoke aphasic or anarthric, and then would be greatly terrified. Usually she wept bitterly on coming out of areatly night, if awake withont having had fit she out of a fit; at night, if awake without having had a fit, she seemed peevish and matle even "finting and striking the mit the eyes.wer "fid probable that they were jerked the the mored slowly to the lelt, as if the opposite group of muscle were weak. The light arm was paretic after the fits, and the right side of the mouth drooped more. In less than 1 per cent. of the fits there was opisthotonus instead of emprosthotonos. These fits, solely nocturnal, occurred every ten minutes or more all through the night. 


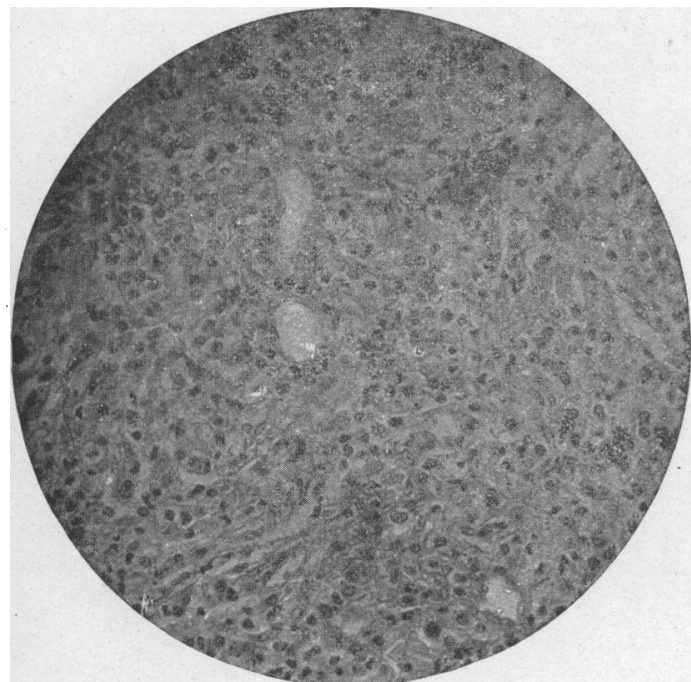

Fig. 1.-Case I, early stage. The section has the characters of granulation tissue.

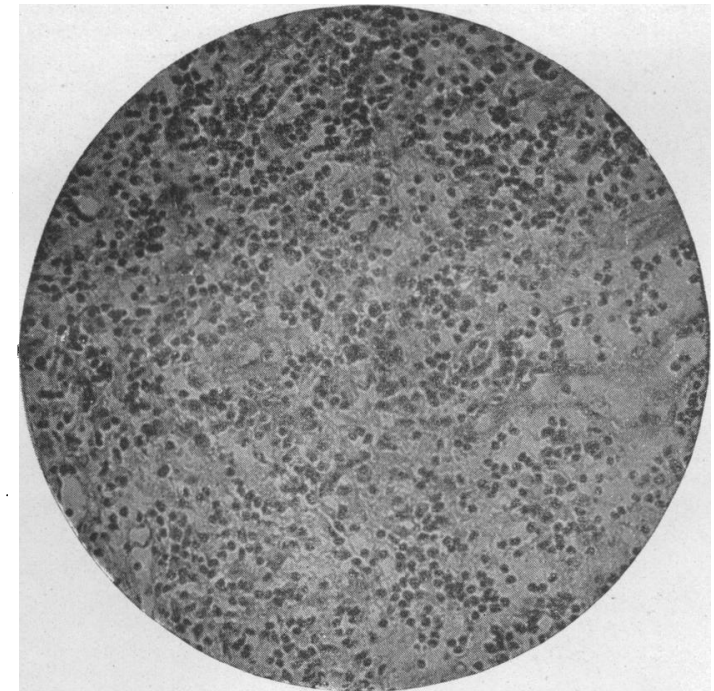

Fra. 3.-Case Ir, early stage. The blood vessels resemble those of granulation tissue, and there are numerous polymorphs present. There are also many large multinucleated cells.

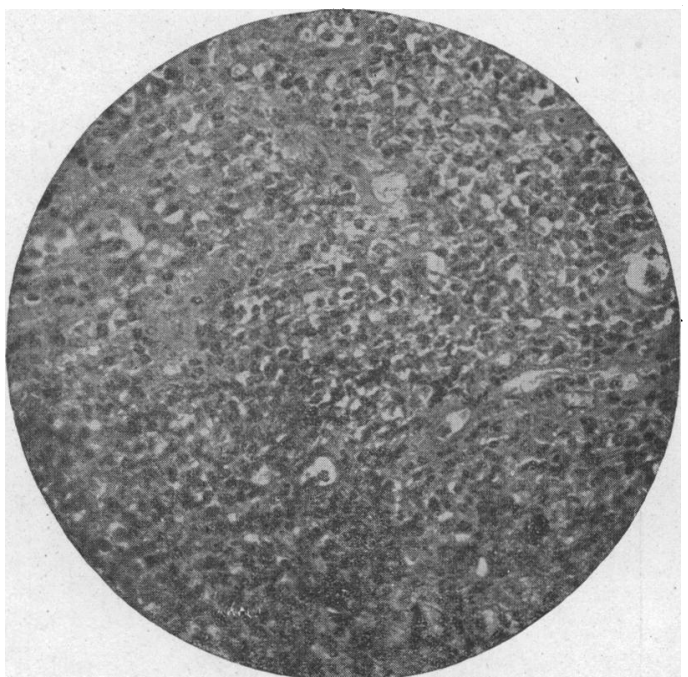

FIG. 2-Case I, later stege. The cells are more irregular in shape, size, and distribution.

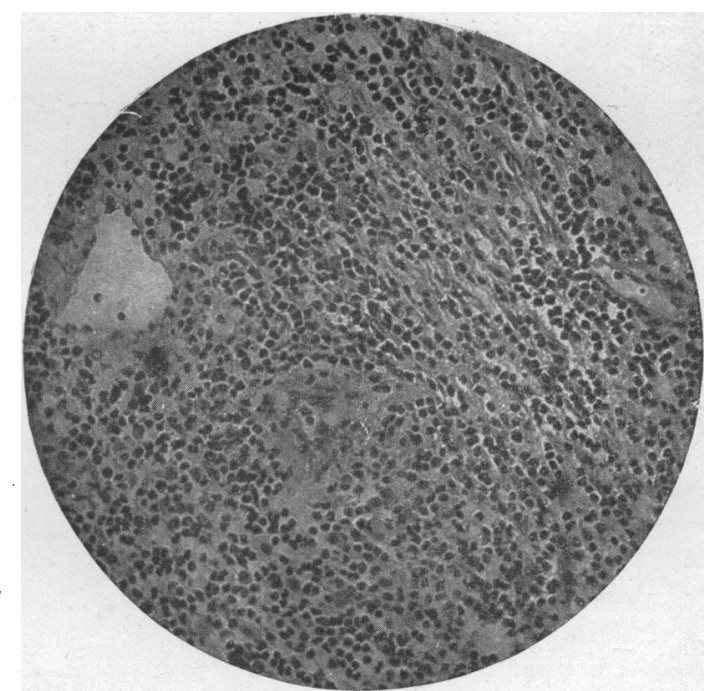

Frg. 4.-Case II. later stage. The round cells are more numerous and have a tendency to lie in rows. The large multinucleated cells are also present.

('The microphotographs were taken by Professor Alriun Stokes.)

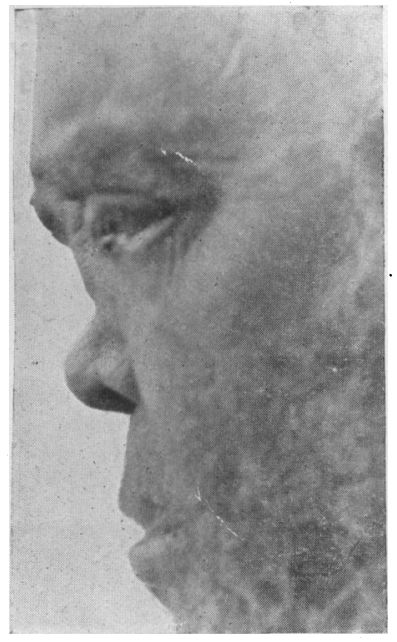

Fia. 5.-Case I

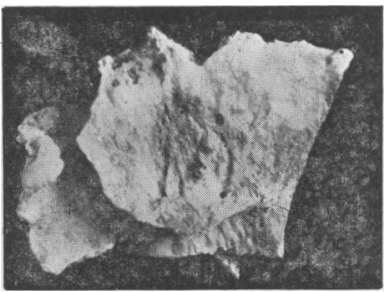

FIG. 7.-Case II, inner aspect.

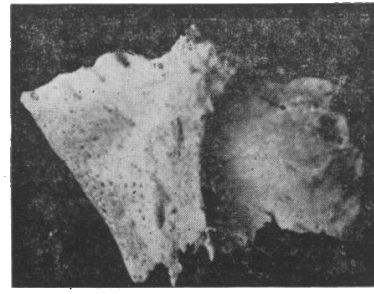

FIG. 8.-Case II, outer aspect.

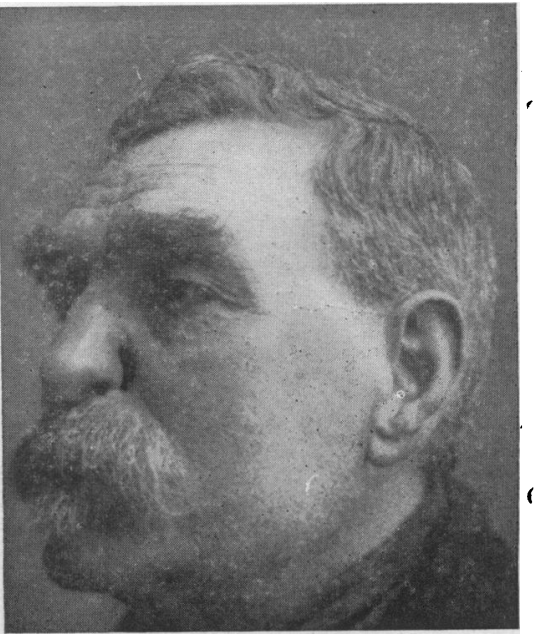

FIG. 6.-Case II. 